\title{
Environment and Philosophy: The Aesthetics and the Natural Environment
}

\author{
Christos A. Tsekos ${ }^{1 *}$, Thaleia Petsiou ${ }^{2}$ \\ ${ }^{1}$ Department of Environmental and Natural Resources Management, University of Patras, Patras, Greece \\ ${ }^{2}$ Department of Agricultural Technology, Technological Educational Institute of Epirus, City, Greece \\ Email: *ca.tsekos@yahoo.gr
}

How to cite this paper: Tsekos, C.A. and Petsiou, T. (2018) Environment and Philosophy: The Aesthetics and the Natural Environment. Voice of the Publisher, 4, 13-21.

https://doi.org/10.4236/vp.2018.42002

Received: February 26, 2018

Accepted: June 9, 2018

Published: June 12, 2018

Copyright (c) 2018 by authors and Scientific Research Publishing Inc. This work is licensed under the Creative Commons Attribution International License (CC BY 4.0).

http://creativecommons.org/licenses/by/4.0/

(c) (i) Open Access

\begin{abstract}
In this study, after initially identifying the field of Aesthetics and the concept of Aesthetically Remarkable (Beautiful), we are going to analyze the aesthetic categories, which constitute a basic element of Aesthetics, taking into consideration that these aesthetic categories are of primary importance regarding the evaluation of the so-called Aesthetically Remarkable. Subsequently, after the interpretation of the term "Environment", we are going to elaborate on a significant change in contemporary Aesthetics that is related to the Aesthetics of the natural environment (not only of Art as before), the similarities and differences of the Beautiful in Art and the Nature and the role of Environmental Policy in protecting the beauty of our natural habitat.
\end{abstract}

\section{Keywords}

Aesthetics, Aesthetically Remarkable, Aesthetic Categories, Beautiful in Art and Nature, Environmental Policy

\section{Introduction}

The aesthetic value of the Natural Environment is apparent. For example, no one could disagree that a sunset or an aesthetic forest is beautiful. The assessment of the aesthetic value of the Environment becomes more important when one considers the major current environmental problems, such as climate change, loss of biodiversity, ozone layer depletion and a lot of human actions that lead to ecological catastrophe. As it is obvious, a complete banning of technological progress is impossible, but humanity has to discover some "tools" in order to minimize the environmental impacts of technology. Such an example is the process of the Environmental Impact Assessment (that is absolutely necessary for the environmental evaluation of every technical work like a dam, a highway, 
a port etc.) in which the engineer has to evaluate, among other things, the negative effect of the technical work on the Aesthetics of the Natural Environment.

Aesthetics is one of the three main pillars of Philosophy: the first one is Logic, the second one is Ethics and the third one is Aesthetics. While Ontology is related to the understanding of the world around us and Ethics deals with various moral issues, Aesthetics is primarily concerned with the Beauty of Art and the Beauty of Nature. The present article aims at investigating issues such as Aesthetic Categories, the meaning of the Aesthetically Remarkable and the relationship between the Aesthetics of Art and the Aesthetics of Natural Environment.

\section{The Philosophical Aesthetics}

We will try to conceptually approach the term Aesthetics. In other words, we will try to recognize the main subject that this philosophical field is exploring. Thus, we believe that a not well-informed reader will better understand the concept of Aesthetics if we try to work inductively and that is the reason why we start with definitions that have occasionally been attributed to this philosophical field by prominent writers who have dealt with Aesthetics.

In the third part of his work Critique of Judgment, I. Kant discusses questions about the foundation of Aesthetics and writes: "Aesthetics is the ability to judge an object or a mode of representation on the basis of an indifference or indulgence without any interest. The object of such a liking is said to be nice" [1].

F. Schiller in the first of the letters he wrote on Aesthetics notes that "You want, therefore, to allow me to present to you in a series of letters the results of my research into the beautiful and the Art... I will support the case of beauty" [2].

The "patriarch" of dialectical idealism G.W.F. Hegel taught that "We must not accept the limitation of Aesthetics to the beautiful of Art... In our everyday life we are used to talking about nice color, a beautiful sky... and indeed about nice flowers..." [3].

Umberto Eco also does not limit the aesthetic reflection in Art by saying that "We define as aesthetic the problem of the possible objective composition and the subjective terms of a particular experience, which in the current language is called Beauty... Such an experience is not necessarily linked to the artistic work, because we call 'nice', not just a poem or a painting, but a horse, a lion, a woman..." [4].

\section{What Is Aesthetically Remarkable?}

Therefore, Aesthetics is the philosophical branch that deals with everything that has to do with the Aesthetically Remarkable both in Art and in Nature [5] [6] [7]; for example, with what Aesthetically Remarkable is ("judgments of taste" as Kant names these judgments [1]), what its manifestations are, what the source of our admiration and consequently our liking for this is, if there is a difference in appreciation of Art and its appreciation in Nature, if our aesthetic evaluations 
have a subjective or objective character, etc.

As a logical consequence, a question arises as to what we mean when we refer to the Aesthetically Remarkable, which is a concept that is quite or very blurred (undefined) for those who have not been informed about Aesthetics. Every human being that is mentally healthy, of course, can understand the Aesthetically Remarkable. This is perfectly illustrated by the following example: if asked to draw a vertical to a straight line, most of us, as it has been experimentally proven, will construct, spontaneously, a perpendicular to the middle of $A B$, i.e. $A B$ and this happens for reasons of symmetry, since, as Psychology teaches, the sense of Beauty is inherent, but it is not certain that most of us can identify it precisely. Taking into account various definitions (regarding the Aesthetically Remarkable) that have been proposed, we will refer to the definition that expresses us personally, but this, of course, does not mean that our choice excludes other approaches.

We can define as Aesthetically Remarkable everything that comes through the senses of sight and hearing (which are considered to be superior senses, while the rest are considered usable only for human survival) in our consciousness causing our liking (pleasure) or our resentment (dissatisfaction), as it happens for example, respectively, with a rosy east or Greco's painting "Storm in Toledo".

In addition, in relation to the above, it is worth noting that a fundamental characteristic of the Aesthetically Remarkable, as Kant noted it, is the unselfishness (without interest), in which the aesthetic experience must be acquired [1]. If, for example, a florist sees a flowering garden with fine flowers as a good commodity for his store, then we cannot speak of aesthetic experience, since in this case personal interest enters into consciousness rejecting at the same time any kind of aesthetic experience. The same would happen if a beautiful church was seen only as a place of fulfillment of our religious duties.

We will achieve a better perception of the notion of Aesthetically Remarkable if we examine the so-called "Aesthetic Categories" by the aesthetic philosophers, in other words the "nuances", in which the Aesthetic Remarkable appears. Lalo discovers nine variants of the Aesthetically Remarkable: a) beauty, greatness, grace, b) sublime, tragic, dramatic, and c) smart, comical, ridiculous [8].

Among the different variants proposed for the categories of aesthetic value we will present three opposite pairs, namely: 1) Beautiful-Ugly, 2) Sublime-Cute and 3) Tragic-Comic and then we will give some basic characteristics of these variants [9].

1a) The Beautiful: if we define harmony as a combination or combinations that make our liking, i.e., mental pleasure, then, in order to have the concept of nice, the following must happen in the dimension of space and in the dimension of time.

In space:

- Harmony in space and shapes (symmetrical arrangement that creates pleasure, e.g. architecture, sculpture, facial or body beauty). 
- Color harmony (combination of pleasant colors, e.g. painting, rainbow).

In time:

- Sound harmony, i.e. a combination of pleasant sounds such as the variety of sounds while a nightingale or a goldfinch trills.

- Kinetic harmony (such rhythm of movements that creates pleasure, e.g. dance).

It is worth mentioning here that besides these basic characteristics for the creation of the Beautiful there are also some others, like for example in the field of Music the variety of tonalities, the sweetness of the musical phrase (e.g. Mozart), the transformation in the change of tone, etc., which will not be analyzed in the present article.

1b) The Ugly: Ugly is, undoubtedly, the opposite of Beautiful causing our displeasure, such as a deep, narrow, anhydrous and arid rocky canyon or a person with asymmetric characteristics, in other words the disharmonic in general [10]. Therefore, it is very impressive to incorporate things that repel us into the Aesthetically Remarkable. Let us remember, however, that in the definition of the Aesthetically Valuable we have referred to the "emotional movement" of the soul and the displeasure is also a feeling that Psychology calls antipathy feelings. And the Ugly, in its all versions, emotionally moves the human soul, as it happens with a wrong combination of colors, with a dissonant melody, with an anti-aesthetic natural scenery, etc. [10].

2a) The Sublime (or High): The first British philosopher and aesthetician Edmund Burke who wrote about this aesthetic category tried to interpret it psychologically [11]. Burke's theory was later adopted by Kant [12] and is an idea that has been supported by almost all Aestheticians.

A special feature of the Sublime in Nature is the excessive size (in volume, weight, height, strength, etc.), as it may be observed, for example, in a cyclone or in the pyramids of Egypt or in the Beethoven's Nine Symphony. In the last part of this Symphony Beethoven incorporated Schiller's "Hymn to Joy" and this way emerges a magnificent harmony.

Since the magnitude or the greatness that characterizes these natural phenomena (such as the cyclone) or these artistic creations usually exceed the ordinary human potential, the feelings that are created are not only awe and wonder, but also admiration and respect.

It has not escaped our notice that the artistic movement of Romanticism often uses this variation of the Aesthetically Remarkable in its effort to bring out intense passions of the human soul, e.g. a night storm illuminated with lightning [12].

2b) The cute: This aesthetic category is the opposite of the Sublime and is related to small-sized things that charm, like a beautiful pebble or a piece of fine art, e.g. a beautiful ring.

3) The tragic and the comic: We do not think we need "recommendations" for these aesthetic categories, since we all know something about them: just the first 
kind often leads to tears and the second kind to laughs, for example the ancient Greek tragedies and the comedies of Moliere respectively.

\section{Aesthetics and Natural Environment}

At this point we should determine exactly how we understand the concept of the Environment and, consequently, what the present paper is. Hence, the concept "Environment", from a purely scientific point of view, should be understood as all the beings and conditions found in the space and time around humankind and belong either to the so-called non-living nature (the abiotic component of the Environment) or to the so-called living nature (the living component of the Environment, to which, of course, humankind belongs).

Nevertheless, for the fullest definition of the concept "Environment", a clarification is necessary: since humankind exists (among many other species) in the living nature, in the broader sense of the Environment we must include their cultural creations, both technological and cultural [13].

So if we want to give a comprehensive overview of the breadth of the concept of the Environment, we consider that we should adopt the following schematic representation [14] [15]. This representation is shown in Table 1.

The present paper will focus on aesthetic issues concerning the natural environment, i.e. the Aesthetics of living and non-living Nature.

Art certainly emerged from the admiration of the Beauty of Nature, but it was wrongly considered by ancient people to be an imitation of Nature (for example, Aristotle wrote in his Poetics that tragedy is "a mimic of great and finest acts..." while Plato accuses Art of being a forgery of truth, since it represents the reality that is a mere appearance and not the truth that lies only in the world of ideas). This happens due to the fact that Art often imitates Nature not passively, but creatively, given the impression that the artist does not simply "photograph" Nature, but incorporates elements of his/her personality into his/her work: if, for example, some artists are asked to portray the same landscape, only the ones that are not talented will "photograph" the reality, while the true artists will create, that is, they will give the landscape through their personal aesthetic perception, e.g. combining the colors so that the landscape may be better than the natural.

However, philosophical thinking was not always interested in the concept of the Aesthetically Remarkable in Nature but it limited itself to the Beautiful (in

Table 1. Definition of the environment.

\begin{tabular}{|c|c|c|c|}
\hline \multirow{2}{*}{ NATURAL } & \multicolumn{3}{|c|}{ ANTHROPOGENIC (i.e. human creations) } \\
\hline & Built & Social & Cultural \\
\hline $\begin{array}{c}\text { Living and non-living } \\
\text { nature }\end{array}$ & $\begin{array}{l}\text { - Settlements } \\
\text { - Infrastructure works, } \\
\text { e.g. roads } \\
\text { ports } \\
\text { airports }\end{array}$ & $\begin{array}{l}\text { - Means of production } \\
\text { - Transportation } \\
\text { - Urban activities } \\
\text { - Agricultural activities }\end{array}$ & $\begin{array}{l}\text { - Cultural monuments, } \\
\text { e.g. traditional buildings } \\
\text { - Historical monuments } \\
\text { - Folklore }\end{array}$ \\
\hline
\end{tabular}


the broadest sense of the term) in Art. The absence of systematic research regarding the Aesthetically Remarkable in Nature until Kant's era (end of the eighteenth century) is implied indirectly even by the name of Aesthetics before Kant, e.g. Philosophy of the Beautiful, Philosophy of the Good (meaning the Art) and above all, and literally, the Philosophy of Art, a term that has been used until nowadays.

Immanuel Kant was the first who (at the end of the eighteenth century) dealt extensively with the Aesthetically Remarkable (Beautiful) in Nature in his two works entitled Critique of Judgment and Observations on the Feeling of the Beautiful and the Sublime [16]. In the second of his two works, Kant wishing to subdue the aesthetic category of the Sublime uses lyricism (i.e. expression of emotions through images of Nature) extolling in this way the Aesthetically Remarkable of Nature: "Those who have the feeling of the Sublime are led to the high sentiments of friendship, eternity, contempt of the world, in the peaceful silence of a summer night, when the tremulous shimmering of the stars runs through the dark night and the moon appears lonely in the firmament" [12]. In our opinion, this Kant's poetic excitement about the aesthetic value of Nature is really beautiful.

Two issues arise in relation to the Aesthetically Remarkable in Nature. 1) whether this, i.e. the Aesthetically Remarkable in Nature, is of equal value to the Aesthetically Remarkable of Art; and 2) which of them is superior (between the Aesthetically Remarkable in Nature and the Aesthetically Remarkable in Art).

Regarding the first issue, we think it is clear that there are similarities between the aesthetic assessment of Nature and Art, but this does not mean that there are no differences that give a special meaning to the aesthetic evaluation of these two fields.

In relation to the similarities, it is important to note that in the above-mentioned analysis of the Aesthetic Categories, each time we explained each one of them, we gave examples from both Nature and Art and we mentioned, for example, that humankind understands the Aesthetic Remarkable both in front of the huge height of a terrific mountain and under the columns of an ancient Egyptian temple: the large size (aesthetic category of the Sublime or High) is not a privilege only of Nature or only of Art. The criterion of human assessment is the same in both cases, but in the first case we are talking about "immersion" [16] [17], while in the other for external observation, as we will see later.

The differences are not related to how we experience the Aesthetic Categories, but to what precedes them before they reach our consciousness.

The first differentiating factor lies in who the creator of the Beautiful is (by using the word Beautiful we mean the aesthetically valuable in general). In the case of Art, due to the fact that the creator is a human being, in the work of Art we search for its meaning, its message or whether the Art belongs to the Art stream "Art for Art", the meaning of its creation; in other words, in Art we face a kind of conscious act, the conscious expression of the creator, the externalization 
of the emotional burden of a soul. In Nature, however, an act belongs to randomness, e.g. whether or not a sunrise or an east are filled with purple or black clouds or whether the volumes are symmetrical or they are not determined by chance. This, of course, gives different characters (different quality in other words) to the Beautiful of Art and the Beautiful of Nature, without this meaning any kind of superiority. A significant point to consider is that the Beautiful in Nature is an unconscious event, while the Beautiful in Art is the conscious work of a personality.

This distinction indisputably has its consequences regarding the aesthetic effect: in the first case, since the creator is a human being (a person) the appraiser is not free in their appreciation. This happens because since artist appears as a "mediator" (a provider of the Beautiful), therefore his or her personal beliefs and personal style influence the appraiser. In the second case the appraiser of the work of Art is free from the creator's limitations, possibly influenced only by personal experiences, e.g. cultural, mythological, natural, religious etc.

Another difference is the variability of the aesthetic value of Nature: on the one hand an artwork can not change, while on the other hand the Aesthetically Remarkable in Nature may not only change but even be transformed into the exact opposite aesthetic category due to the time or weather conditions or human intervention. Let us think the example of a beautiful landscape in the middle of spring after a storm that can be transformed into ruins. From our point of view, this fleeting natural beauty is one of the reasons that have forced people to create Art: is there a reason to wait for spring to come and not have a painting showing a beautiful spring landscape in our living room?

The third and most important, according to us, dissimilarity concerns the personal relationship of the estimator with the object of estimation: in Art we are always "outside" the object of estimation as Aesthetically Remarkable; that is, a "dead "relationship between human and art, while in Nature, a phenomenon that scholars of Aesthetics call "immersion" happens [16] [17]. In this last case we are deeply involved in the Aesthetically Remarkable (we are literally within it) when we find ourselves walking into a beautiful forest, smelling it and cutting some of its wildflowers. On a huge mountain we can climb to the top of it, grasp the snow and feel the vertigo of the unpredictable height alive; in a storm we are at the mercy of Nature and we may be in danger. This direct engagement with the Beautiful in Nature, we think it is a different aesthetic experience than what a painter with his paintbrush or a poet with his lyrics would give us. As far as the second issue is concerned, which was mentioned just before, we reiterate that there is no qualitative difference between the Beautiful of Nature and the Beautiful of Art: each one has its own value, and both of them are important to the satisfaction of the inherent human need for the Aesthetically Remarkable. Consequently, both an ancient Greek tragedy and an aesthetic forest are equally important factors to the symmetric development of the three dimensions of our soul (according to Plato: knowledge, emotion, desire). 
And if some people argue that Art, in most of its creations, leads humankind to morality, Kant (in the Critique of Judgement) will answer that: "On the contrary, I argue that having a direct interest for the beauty of Nature (not simply to have a taste for judging it) is always a trait of a good soul, and when this interest is a habit, it shows at least a positive spiritual predisposition to moral emotion" [1].

As regards whether the aesthetic value of Nature or Art is superior, one can put forward the following view: how is it possible to find in Nature such combinations of sounds that human creates with Music?

Personally we have the following view on this issue. Obviously, humankind has developed (evolved) many beautiful things that have been found in Nature, but that does not seem to give us the right to evaluate everything in this case; the beautiful is beautiful either it comes from a nightingale singing or from a musical piece of any kind. In this case we can not make an axiological judgment because it is a development of the aesthetic experience. Let us not forget that we also have an evolution in the field of Ethics: animals take care of their little ones (inherently, of course, but this is no longer a moral act), but humankind has importantly evolved their morality in order to include animals [18] [19].

To sum up, it is important to note that Beautiful remains Beautiful either it comes from the trilling of a bird or from a four-person choir. In the second case we have an expression of the Aesthetically Remarkable.

\section{Conclusions}

The main objective of Aesthetics is the study (from a philosophical point of view) of the Aesthetically Remarkable which includes whatever can activate our emotions and which appears having various forms in Art as well as in Nature. Initially, Aesthetics attached great importance only to the concept of the Beautiful in Art and only in recent years there have been aesthetic studies dealing with the Beautiful in Nature. Both the Beautiful in Art and the Beautiful in Nature give equally rise to the aesthetically valuable, but there are undeniably differences between these two kinds of Beautiful.

Among the various side effects caused by the harsh modern homo Faber on the Environment (pollution, effects on human health etc.), it is now evident that the Beauty of Nature has been destroyed, mainly for reasons related to economic profit and two examples are typical: sacrificing a beautiful forest to become a quarry and destroying a marvellous beach for tourist reasons. We are not, of course, against economic growth, but let us always keep in mind, especially those who shape Environmental Policy (in which citizens must have a more active role), that human hubris is the basic factor that leads us constantly to the privation of Nature's Beauty.

\section{Acknowledgements}

I am deeply indebted to Miss Lina Efstathopoulou for her valuable assistance in 
preparing the manuscript for publication, including revisions on the original draft.

\section{References}

[1] Kant, I. (1997) Critique of Judgement. Pluhar, W. Translation, Hackett Publishing Company, Indianapolis.

[2] Hegel, G.W.F. (1995) Vorlesung über Ästhetik (Berlin 1820/21): Eine Nachschrift. Peter Lang, Frankfurt am Main.

[3] Schiller, F. (1995) About the Aesthetic Education of the Man. Androulidakis, K. Translation, Ideogramma Publications, Athens.

[4] Eco, U. (2004) Storia Della Bellezza. RCS Libri Bombiani, Milano.

[5] Tzavaras, G. (2007) Anthology of Aesthetics. Gutenberg Publications, Athens.

[6] Glykogrydi-Leontsini, A. (2008) An Introduction to Aesthetics. Symmetria Publications, Athens.

[7] Audi, R. (1995) The Cambridge Dictionary of Philosophy. Cambridge University Press, Cambridge.

[8] Lalo, C. (1954) Aesthetics. Govostis Publications, Athens.

[9] Papanoutsos, E. (1980) Aesthetics. Dodoni Publications, Athens.

[10] Eco. U. (2007) Storia Della Bruttezza. RCS Libri Bombiani, Milano.

[11] Burke, E. (1906) The Works of Right Honourable Edmund Burke. Vol. 2, Oxford University Press, London, New York.

[12] Kant, I. (2003) Observations on the Feeling of the Beautiful and Sublime. Golthwalt, J.T. Translation, California University Press, Berkeley, California.

[13] Bortman, M., Brimblecombe, P., Cunningham, M.A. and Cunningham, W.P. (2003) Environmental Encyclopedia, Vol. 1, Thomson Gale Editions, Michigan.

[14] Munn, T., Mooney, H.A. and Canadell, J.P. (2001) Encyclopedia of Global Environmental Change. The Earth System: Biological and Ecological Dimensions of Global Environmental Change. Vol. 2, Wiley, Chichester and New York.

[15] WCED-World Commission on Environment and Development (1987) Our Common Future: The Report of the World Commission on Environment and Development. Oxford University Press, Oxford.

[16] Pratt, V., Howarth, J. and Brady, E. (2004) Environment and Philosophy. Routledge, London, New York.

[17] Berleant, A. (1992) The Aesthetics of Environment. Temple University Press, Philadelphia.

[18] Light, A. and Rolston, H. (2003) Environmental Ethics: An Anthology. Blackwell Publishing, Oxford.

[19] Attfield, R. (2003) Environmental Ethics. Polity Press and Blackwell Publishing, Cambridge. 